\title{
INVESTIGACIÓN/RESEARCH
}

\section{CUADERNOS AMERICANOS Y REALIDAD: DOS PUBLICACIONES MÁS ALLÁ DEL EXILIO REPUBLICANO EN AMÉRICA}

Ana González-Neira ${ }^{\mathbf{1}}$ : Universidad de la Coruña. España agonzalezn@udc.es

\section{RESUMEN}

El exilio español de la Guerra Civil provocó el nacimiento de centenares de cabeceras republicanas en la diáspora tanto de tipo político como científico o cultural. Dos de esas revistas culturales, Cuadernos Americanos (México, 1942) y Realidad (Buenos Aires, 1947) se erigieron como soporte de la producción intelectual de los refugiados y la elite iberoamericana y europea, hasta el punto de que algunos autores las han clasificado como publicaciones puramente argentinas y mexicanas. Lejos de cerrarse en la rígida jaula del éxodo español, ambas se abrieron tanto al continente americano, como al europeo y a la España del interior. En este artículo se analiza el grado de americanización de estas publicaciones a través del estudio de los temas tratados, el origen de sus colaboradores así como la publicidad e información ofrecida.

PALABRAS ClAVE: Prensa cultural - Revistas - Historia del periodismo - Exilio Redes intelectuales

\footnotetext{
${ }^{1}$ Autor Correspondiente Ana González-Neira: Profesora de la Universidad de la Coruña. España. Correo: agonzalezn@udc.es
} 


\section{CUADERNOS AMERICANOS AND REALIDAD: TWO MAGAZINES BEYOND THE REPUBLICAN EXILE IN AMERICA}

\section{ABSTRACT}

The exile Spanish Civil War gave birth to hundreds of Republican magazines and newspapers. Two of these cultural magazines, Cuadernos Americanos (Mexico, 1942) and Realidad (Buenos Aires, 1947) were founded to support the intellectual production of refugees and the Latin American and European elite, to the extent that some authors have classified as purely Argentine and Mexican publications. Far from being confined in the rigid cage Spanish exodus, both magazines were opened to Americas, Europe and the interior Spain. This essay analyzes the degree of Americanization of both publications through the study of the topics discussed in them, the origin of their staff as well as the advertising and information they provided.

KEY WORDS: Cultural Newspapers - Magazines - Journalism history - Exile Intellectual networks

\section{INTRODUCCIÓN}

El estallido de la Guerra Civil y la posterior victoria franquista provocó el éxodo de decenas de miles de refugiados españoles hacia Europa (principalmente a Francia por la cercanía geográfica) y América. En estos países conformaron una España Peregrina mientras preparaban su ansiado regreso a la Península. Sin embargo, con el paso del tiempo esa confianza en la vuelta se fue debilitando lentamente por los acontecimientos internacionales, si bien los ideales republicanos permanecieron vivos en los cuarenta años de diáspora.

Uno de los elementos básicos para conseguir la permanencia de estos principios republicanos fue la prensa. Desde los primeros días de combate nacieron boletines, revistas y periódicos que servían como plataforma propagandística y soporte para reflexiones, propuestas, ensayos o informaciones del día a día del exilio. Tan sólo en el continente americano surgieron varios centenares de cabeceras, la mayor parte de tipo político, aunque también destacan algunas culturales como España Peregrina, Nuestra España, De Mar a Mar, Litoral oTimón, entre otras muchas.

En América, fue en el campo cultural en donde se produjo una mayor integración entre los desterrados españoles y los intelectuales locales, favorecidos sin duda por las redes establecidas antes de la contienda y la facilidad de la lengua. En un primer momento esta prensa de tipo cultural se centró en temas españoles obsesionados por los episodios bélicos y dispuestos a preparar el regreso a la Península, no obstante, una vez finalizada la II Guerra Mundial asumieron que su vuelta no sería inmediata y se favoreció la apertura a los ambientes de acogida. 
En este trabajo se analizarán dos revistas culturales fundadas por manos refugiadas en el Nuevo Continente con el objetivo de ahondar en su naturaleza americana, ya que en numerosas ocasiones se las ha considerado parte de la prensa nacional de los países en los que nacieron. Se trata de Cuadernos Americanos durante los años en

los que estuvo al frente el desterrado Juan Larrea (1942-1949) ${ }^{1} \mathrm{y}$ Realidad. Revista de ideas (1947-1949). Se investigarán las semejanzas y diferencias de ambas publicaciones de cara a evaluar su naturaleza.

\subsection{Presencia exiliada en sus orígenes}

En ambos casos son revistas impulsadas por exiliados de la Guerra Civil. Cuadernos Americanos nace en los primeros días de 1942 tras las gestiones realizadas por el bilbaíno Juan Larrea y León Felipe tras el fracaso de la publicación España Peregrina. Los problemas económicos que había padecido la Junta de Cultura Española así como los enfrentamientos entre Larrea y Bergamín habían conducido al cierre de esta última. Es entonces cuando Larrea toma conciencia de la necesidad imperante de abrirse al continente americano, elemento básico de sus reflexiones teleológicas.

Ante la difícil situación financiera de España Peregrina, Larrea consulta al periodista Octavio Barreda y al poeta Bernardo Ortiz de Montellano (ambos mexicanos) sobre quién podría proporcionarles publicidad para sanear sus cuentas; su respuesta fue la misma: Jesús Silva Herzog. Por lo que en febrero de 1941, León Felipe, Bernardo Ortiz de Montellano y Juan Larrea acudieron a hablar con Silva Herzog a su despacho de Estudios Económicos de la Secretaría de Hacienda. Tras varias reuniones deciden lanzar Cuadernos Americanos.

Respondiendo a una estrategia de tipo comercial, como director-gerente constaba en la mancheta Silva Herzog mientras que como Secretario aparecía Larrea. En realidad ambos se habían repartido las duras tareas que acompañan la creación y mantenimiento de una revista como si se tratara de un núcleo familiar. De la unión de ambas voluntades surgió esta cabecera que procedía de una "madre" española de un "padre" mexicano según el propio Larrea le escribe en una carta de 1950 a Silva Herzog:

Como ya le escribí en otra ocasión, no faltan razones para considerarme a mí, la 'madre' de Cuadernos...Supongo que no tendrá usted reparo en reconocerme, inter nos, dicha 'maternidad'. (...) Ahora bien, no creo que nadie pueda discutirme con justicia la maternidad de la criatura, puesto que todos los caracteres de esa su originalidad, tanto los externos como los internos, le llegaron por mi cauce. ${ }^{3}$

12 En 1949 en plena crisis personal de Larrea, éste abandona su cargo de secretario y la publicación inicia una trayectoria más americanista que llega hasta hoy en día 
Siguiendo su símil de los progenitores, Silva Herzog actúa como padre que trabaja fuera de casa para traer el dinero, mientras Larrea aparece como la madre que se entrega al hogar, atiende a los hijos, lleva la casa para que el fruto, en este caso la revista, crezca firme y fuerte. Recordemos que en la misiva de 1950 le escribe a Silva Herzog:

Entiendo que esa 'maternidad' que he venido atribuyéndome se encuentra certificada por mi dedicación íntegra, abnegada, sacrificada incondicionalmente a la perfección y el mejor desarrollo de la revista, sin aprovechamiento, afectación y alardes, que suele ser la de las madres hacia sus hijos. ${ }^{4}$

La financiación de la cabecera corría a cargo de las importantes amistades que el economista Silva Herzog poseía. A través de sus óptimos contactos con el Gobierno conseguía la publicidad de empresas estatales como la Nacional Financiera, Altos

Hornos de México, Ferrocarriles Nacionales de México (FNM) o Lotería Nacional. Fue éste uno de los pilares sobre los que se sustentó la continuidad de Cuadernos Americanos y se evitó caer en la habitual situación deficitaria de la prensa cultural. Por el contrario, Larrea y León Felipe no consiguieron ninguna aportación del gobierno republicano de Negrín, por lo que no hubo apoyo económico español a la revista.

Su Junta de Gobierno la integraban cinco refugiados y seis mexicanos: Pedro Bosch Gimpera, ex rector de la Universidad de Barcelona; Eugenio Ímaz, profesor de la Universidad Autónoma de México; Juan Larrea, ex secretario del Archivo Histórico Nacional de Madrid; Manuel Márquez, ex decano de la Universidad de Madrid; Agustín Millares Carlo, catedrático de la Universidad de Madrid; Daniel Cosío Villegas, director general del Fondo de Cultura Económica; Mario de la Cueva, rector de la Universidad Nacional Autónoma de México; Manuel Martínez Báez, presidente de la Academia de Medicina de México; Bernardo Ortiz de Montellano, ex director de Contemporáneos ${ }^{5}$; Alfonso Reyes, presidente de El Colegio de México y Jesús Silva Herzog, director de la Escuela Nacional de Economía de México.

\footnotetext{
${ }^{3}$ Cito por FINISTERRE, Alejandro (1992): “Juan Larrea, León Felipe y el cincuentenario de Cuadernos Americanos", en Cuadernos Americanos, № 35. Pág. 123 y 128. Alejandro Finisterre publica en 1992 el mismo artículo, con igual título y contenido, en el no 501 de Cuadernos Hispanoamericanos, pág. 89100

${ }^{4}$ Finisterre, A. (1992). Juan Larrea, León Felipe y el cincuentenario de Cuadernos Americanos. Cuadernos Americanos, (35), 129.

${ }^{5}$ En los nombres de los miembros de la J unta de Gobierno de la revista que figuran en el número tres despareció el de Ortiz de Montellano y en su lugar se insertó el del también mexicano Alfonso Caso, por aquel entonces, director del Instituto Nacional de Antropología e Historia de México. Continúa así hasta que en el o 1 de 1949 aparecen los mexicanos Antonio Carrillo Flores y Manuel Sandoval Vallarta en
} 
Realidad nace en 1947 impulsada por los desterrados españoles Francisco Ayala y Lorenzo Luzuriaga, aunque la idea original procedía de un intelectual argentino. Según confiesa el granadino: "La de lanzar una nueva revista en Buenos Aires fue idea de Eduardo Mallea, quien - con todos los circunloquios, reservas, precauciones y reticencias propios de su carácter - me la brindó a mí"(Ayala, 2001, p. 342).

A pesar de que oficialmente consta como director Francisco Romero, al mando de la misma estuvieron los refugiados mencionados oficialmente nombrados secretarios de redacción. Al igual que en Cuadernos Americanos, su consejo de redacción tiene una carácter mixto ya que se compone de los españoles Amado Alonso ${ }^{6}$, Francisco Ayala, Lorenzo Luzuriaga, Julio Rey Pastor y los argentinos Carlos Alberto Erro, Ezequiel Martínez Estrada, Carmen R. L. de Gándara, Eduardo Mallea, Raúl Prebisch y Sebastián Soler ${ }^{7}$. Más tarde se incorporarían Guillermo de Torre y J osé Luis Romero.

Económicamente, la revista nace gracias a los capitales de otras empresas vinculadas al exilio, las editoriales Losada y Sudamericana, la imprenta López así como la mecenas Carmen Gándara. Como es habitual en este tipo de publicaciones los problemas económicos no se hicieron esperar y estuvieron detrás de su cese. Fue ésta la excusa que aprovechó Ayala para cerrarla en 1949:

al agotarse los fondos económicos de la revista (que Luzuriaga y yo conseguimos estirar hasta tres años en lugar de los dos calculados de antemano), rechacé las ofertas de nuevo capital que desde otras fuentes se me hicieron, y 'aquí paz y después gloria': se terminó Realidad, revista de ideas. ${ }^{8}$

Por lo tanto, comprobamos que en ambos casos existe una voluntad exiliada en el origen de estas revistas pero el apoyo mexicano y argentino se convirtió en imprescindible para sacarlas adelante, fue la chispa que prendió los motores de Cuadernos y Realidad. La unión de estas dos fuerzas dio lugar al nacimiento de estas decisivas publicaciones.

\section{METODOLOGÍA}

En los análisis de los resultados descritos en el presente artículo de investigación se emplearos diversos métodos empíricos, de ellos el análisis documental para la construcción del marco teórico de referencia, especialmente para contextualizar la situación problémica.

\footnotetext{
sustitución de Mario de la Cueva y Agustín Millares Carlo. En el no 6 de 1949, no figura Juan Larrea en la Junta de Gobierno ni como secretario. En su lugar consta Daniel Rangel como secretario y Loera y Chávez como editor. La presencia española en la J unta de Gobierno se reduce a tres desterrados: Pedro Bosch Gimpera, Eugenio Ímaz y Manuel Márquez.

${ }^{6}$ Residente en Argentina cuando estalla la guerra, no es propiamente exiliado aunque siempre manifestó su compromiso republicano

${ }^{7}$ Nacido en Sallent de Llobregat pero residente en Argentina desde muy joven

${ }^{8}$ Ayala, F.(2001). Recuerdos y olvidos. Madrid: Alianza Editorial, p. 346
} 
En este mismo orden de ideas se empleó el método teórico del conocimiento: histórico lógico, para la interrelación de los distintas propiedades históricas del objeto de investigación mediante un hilo conductor lógica de espacio temporal.

Finalmente el método de la generalización fue empleado para analizar el grado de americanización de estas publicaciones a través del estudio de los temas tratados, el origen de sus colaboradores así como la publicidad e información ofrecida.

\section{ANÁLISIS Y DISCUSIÓN}

\subsection{Revistas culturales comprometidas con la realidad}

En ambos casos estamos ante cabeceras culturales de carácter científico, definidas por el pensamiento de sus impulsores Larrea, Ayala y Luzuriaga. Por lo que respecta a Cuadernos Americanos, entre los planes iniciales de Larrea estaba "la creación de una gran revista, la más importante revista en lengua castellana que, en aquel momento en que ardía Europa por sus cuatro costados, fuese producto de la estrecha colaboración creadora de hispanoamericana y españoles, con miras a preparar el advenimiento de una cultura más universal, más humana" (Larrea, p.84). Y así fue, cumplió esta cabecera ese compromiso con la cultura que manifestaba su única declaración de intenciones del número inicial: "En los actuales días críticos un grupo de intelectuales mexicanos y españoles, resueltos a enfrentarse con los problemas que plantea la continuidad de la cultura, se ha sentido obligado a publicar Cuadernos Americanos Revista bimestral dividida en cuatro secciones".

A diferencia de Realidad, centrada en el campo de las humanidades, Cuadernos concibe una extensa temática de ensayos conforme a su amplia idea de cultura ${ }^{9}$. No se limita a los campos sociales del conocimiento como pudieran ser la literatura, historia o política, sino que aborda cuestiones novedosas en este tipo de cabeceras como las matemáticas, química, filosofía de la ciencia u óptica. Es además, una de las pioneras en incluir textos de arqueología, ciencia que daba sus primeros pasos precisamente en ese momento. Bajo la perspectiva larreana, la cultura naciente debía contemplar todos estos campos lejos de algún reduccionismo:

La división de la revista en cuatro secciones, con cuatro nombres poéticos distintos correspondientes a los cuatro grandes horizontes creadores en cuya confluencia está situada. Estructuralmente, representa la unión de cuatro revistas complementarias, acordadas orgánicamente a la consecución de un solo fin. ${ }^{10}$

En este sentido Liliana Irene Weinberg le da el rasgo de omnívora, un calificativo que a su entender " (...) no implica de ningún modo otorgarle un carácter de acumulación

\footnotetext{
${ }^{9}$ En este sentido véase el artículo de Alfonso Reyes, "América y los Cuadernos Americanos", Cuadernos Americanos, no 2, (1942). Pág. 7-10.

${ }^{10}$ Plasmados en la carta enviada a Silva Herzog en julio de 1950. FINISTERRE, Alejandro (1992): "Juan Larrea, León Felipe y el cincuentenario de Cuadernos Americanos", en Cuadernos Americanos, ㄲo 35. Pág. 128
} 
de textos sin signo definido, sino, muy por el contrario, enfatizar una de sus características fundamentales: la búsqueda apasionada y plural del conocimiento y el debate sobre América Latina" (Weinberg, 1995, p. 16). Abordaba América desde todas las perspectivas.

Cuadernos Americanos se entrega a la defensa de la cultura al considerarla elemento clave en la lucha por la justicia y la democracia. Sus responsables y colaboradores sentían el deber moral y el compromiso que les obligaban a protegerla ante los embates de quienes la ignoraban o instrumentalizaban con el objeto de controlar 0 aumentar el poder. Alfonso Reyes se refiere a ella y al papel de las naciones americanas en ese difícil momento, durante su intervención en el acto de presentación de la revista:

Entendemos nuestra tarea como un imperativo moral, como uno de tantos esfuerzos por la salvación de la cultura, es decir, la salvación del hombre. (...) La cultura es el repertorio del hombre. Conservarla y continuarla es conservar y continuar al hombre (...) ha caído en nuestras manos la grave incumbencia de preservar y adelantar la religión, la filosofía, la ciencia, la ética, la política, la urbanidad, la cortesía, la poesía, la música, las artes, las industrias y los oficios: cuanto es lenguaje que guarda y transmite las conquistas de la especie, cuanto es cultura en suma. América es llamada algo prematuramente a tal incumbencia. ${ }^{11}$

El cumplimiento de la misión enunciada por Alfonso Reyes implica estar atentos a la actualidad, a la realidad que están viviendo para ofrecer textos analíticos de los acontecimientos. Cuadernos durante estos años es testigo del final de la II Guerra Mundial, los acuerdos de paz y los primeros pasos de la Guerra Fría. En sus páginas se reflexiona sobre todo ello y acerca del papel que América debería desempeñar en este nuevo contexto.

También en las páginas de Realidad es patente el compromiso con la cultura. Inicia la presentación de esta cabecera:

Nuestra cultura - la vieja e ilustre cultura de Occidente- ha llegado hoy a una situación excepcional. Por una parte, atraviesa formidable crisis; por la otra, se halla en la obligación de proporcionar al mundo entero - ya no exclusivamente a lo que era hasta ahora su propio ámbito- un programa completo de vida y de pensamiento, porque el proceso de unificación mundial que venía avanzando desde hace tiempo se ha acelerado prodigiosamente en los últimos años, por razones y en maneras tan varias como bien conocidas, haciendo de todo el planeta una sola unidad. Este es el hecho gigantesco que debe afrontar el hombre occidental: su cultura, quebrantada por una crisis gravísima, tiene que asumir plenamente el carácter y la función de cultura universal. ${ }^{12}$

\footnotetext{
${ }^{11}$ Reyes, Alfonso (1942). América y los Cuadernos Americanos. Cuadernos Americanos ( 2), 7-10.

${ }^{12}$ Realidad (1947, enero-febrero). Revista de ideas, (1), p 1
} 
A diferencia de Cuadernos, y para no erigirse en competidora de Sur donde escribían varios de los colaboradores e incluso el propio Ayala, Realidad posee "un sesgo marcadamente ensayístico y crítico, excluyendo de sus páginas los textos de pura invención poética, verso o prosa, que predominaban en las páginas de Sur"13 Asimismo, quedan fuera de sus páginas ensayos sobre cuestiones científicas como sí había abordado la revista de Larrea.

El editorial del primer número insiste en su voluntad de no volcarse en el campo de la literatura como creación:

Una revista que no quiere ser literaria en el sentido habitual de la palabra, ni tampoco especializada en un grupo aislado de problemas teóricos o prácticos, tiene naturalmente como programa la consideración de la vida de la cultura, y la forma como ello se realice depende en parte de las intenciones previas, pero también, en igual o mayor medida, de las posibilidades y aun de la palpitante contingencia. ${ }^{14}$

Tanto en Cuadernos como en Realidad escogen el género ensayístico como el más adecuado para abordar el análisis y la interpretación de los vértices temáticos ${ }^{15}$. En sus páginas se concentran ensayos de altísimo nivel sobre política, filosofía, literatura, sociología que configuran un crisol de la mejor producción intelectual del Occidente.

No existen artículos informativos en Cuadernos, mientras que en Realidad la sección "La caravana inmóvil" inserta noticias de tipo cultural y comentarios.

Esa declaración de intenciones del número inicial acerca del compromiso con la cultura permanece fiel durante la vida de Realidad ya que en la nota insertada al final del primer año, declaran:

Proseguiremos concitando el examen de nuestra cultura en sus diferentes aspectos y repartiendo la atención sobre los muchos problemas que plantea; especial consideración dedicaremos a las cuestiones de fondo concernientes a la peculiar índole, fundamentos, situación presente y destino previsible del orbe occidental, en la convicción de que es una de la más urgentes cuestiones que debe afrontar la mente contemporánea.

\footnotetext{
${ }^{13}$ Ayala, Fr. (2001). Recuerdos y olvidos. Madrid: Alianza Editorial. p. 343

${ }^{14}$ Realidad (1947, enero-febrero). Revista de ideas, (1), 4. De todos modos, esa declaración se incumplirá con el tiempo, ya que en una nota insertada en el no 6, al cierre del primer año de vida de la revista declaran "Nos proponemos insertar de vez en cuando escritos de pura creación que entendamos ostenten nobles valores literarios". De hecho, el propio Ayala publica su cuento "El Tajo" en el no 16 de esta cabecera.

${ }^{15}$ Revista y ensayo se retroalimentarán en un espacio simbólico donde se piensa con dimensión histórica lo cultural y se representa la tensión entre dos pulsiones características de la hora: incidir en el largo plazo de la cultura a la vez que en el corto plazo de la coyuntura" (Weinberg, 2010 a, p. 303).
} 
Al igual que Cuadernos, esta cabecera pretendía convertirse en foro de análisis y debate de los acontecimientos que vivía el mundo. En un momento de expansión de la doctrina Truman o del inicio de la Guerra Fría muchos interrogantes surgían sobre el futuro del continente. Ambas se erigían como miradores desde los que afrontaban y debatían cuestiones políticas y sociales de la actualidad del momento.

\subsection{Apertura a América}

El elemento que más separa a estas cabeceras de otros ejemplos de prensa de la diáspora es la apertura y atención al continente americano ${ }^{16}$. A diferencia de otras publicaciones como Las Españas 0 el Boletín de Información de la Unión de Intelectuales Españoles, estas revistas no convierten en prioritaria la cuestión del exilio y los debates sobre la recuperación de España. Las causas de esta apertura hay que buscarlas en la personalidad de sus impulsores, Juan Larrea y Francisco Ayala. En ambos casos, al igual que había ocurrido con José Gaos, son refugiados perfectamente acomodados a la nueva situación y que, a través de razonamientos diferentes, no se instalan en un exilio inundado de amargura y nostalgia. En este sentido, reconoce el escritor granadino:

No he tenido lo que se llaman vivencias del exilio; el sentimentalismo del exiliado yo no lo he sentido nunca (...) Lo que se refiere a patria y sentido telúrico son cosas que me parecen completamente imaginativas y yo soy hombre de poca imaginación (Ayala, 1966, p. 34).

Cuadernos se inscribe en la corriente de pensamiento americanista defendida por pensadores como Alfonso Reyes, Waldo Frank o Henríquez Ureña. Para Larrea, América se había convertido en la protagonista de la nueva etapa en la evolución de las civilizaciones. Había sido necesario el sacrificio de la II República y la inmolación del pueblo español para que cuanto representaba aquélla renaciera en América, pues defendía que las convulsiones de Europa fructificarían en un Mundo Nuevo, que él situaba en América. En las páginas de Cuadernos Americanos, como antes en las de España Peregrina ${ }^{17}$, plasmó su teoría: América como salvación de la civilización una vez cumplido el fracaso de Europa. Larrea realiza una correspondencia entre Asia, Europa y América y las figuras de la Santísima Trinidad (Padre, Hijo y Espíritu), y opina que una vez terminada la fase del Hijo (Europa), el protagonismo pasa a América (el Espíritu). Dicho americanismo fungía también como arma de contención de la influencia cultural estadounidense en Iberoamérica.

Por su parte, Ayala huyó de los círculos del exilio y de la nostalgia de España. Es cierto que mantuvo su republicanismo y no olvidó sus orígenes pero se volcó en la

\footnotetext{
16 Habitualmente aparece el término América para aludir a Iberoamérica, es decir, incluían a Brasil y dejaban al margen los estados anglófonos y francófonos

17 Ferriz Roure, T.(2007) Estudio de España Peregrina. Disponible en: www.cervantesvirtual.com/servlet/SirveObras/03695030900370528539079/index.htm (Consultado: 23 de enero de 2007).
} 
adaptación e inmersión en los diferentes países de acogida ${ }^{18}$. Prefirió abrirse a la nueva realidad que las circunstancias le habían brindado a diferencia de otros compatriotas que se asentaron en un nacionalismo españolista exclusivista ${ }^{19}$.

Asimismo, existe una escisión de tipo estratégico. Las publicaciones centradas en España y lo español eran deficitarias por el escaso mercado al que se dirigían. Sin embargo, la apertura a los círculos intelectuales del continente americano, garantizaban una mayor difusión y por lo tanto, mayores posibilidades de supervivencia.

Por lo que se refiere a Cuadernos, esa vocación americanista aparece reflejada incluso desde el propio nombre de la revista, ideado por Alfonso Reyes. Además, ya en el primer número la cabecera se presenta con el subtítulo de "Revista del Nuevo Mundo". En ese número inicial, sobre una imagen de un mapa de América ${ }^{20}$ figura la frase de Francisco Pi y Margall "América, tú eres mi esperanza, tú estás llamada a salvar al mundo" y la de Rubén Darío: "América es el porvenir del mundo". Un español y un americano inciden en valorar el determinante papel del Nuevo Continente. Asimismo, Larrea recuerda que Cuadernos se basa en la:

Creencia de que el continente americano está llamado a realizar los aportes de conciencia necesarios para infundir caracteres de mundo nuevo y distinto a ese todo cultural naciente por ser propio de su destino dar cuerpo, al contacto con la universalidad a una entidad diferenciada, a un hombre y a una cultura nuevos. (...) Una orientación americana por sobre cualquier nacionalismo y sobre el europeísmo, con miras a la universalidad ${ }^{21}$.

Será este último concepto el que una a ambas publicaciones. En el caso de Realidad no existe una declaración firme de compromiso con el continente, si bien se le reconoce un papel decisivo en esos momentos como indica en su presentación:"Debemos aceptar que a América puede estarle reservado un papel capital en la necesaria extensión, presente y futura, al mundo entero, de los principios, modos y normas de la cultura de Occidente". ${ }^{22}$

18 Recordemos que a las pocas semanas de su llegada a Buenos Aires ya colaboraba en las publicaciones argentinas de LaNación y Sur

19 En relación a las presiones de Carmen Gándara para que la revista fuera más argentina, escribe Ayala: "Exiliado como lo era yo, no podía por menos de comparar ese argentinismo ferviente de doña Carmen con el españolismo enragé de tantos refugiados españoles que, desdeñosos desde luego del país donde estaban viviendo, exaltaban por contraste 'lo español', a la vez que condenaban en bloque 'a la España de Franco' y vituperaban acerbadamente a cada uno en particular de sus compañeros de emigración; con lo cual, 'lo español' venía a reducirse en último análisis a una indefinida esencia de la que era portador y custodio exclusivo quien hablaba en cada momento". AYALA, Francisco (2001): Recuerdos y olvidos. Madrid. Alianza Editorial. Pág. 344.

${ }^{20}$ Firmada por el exiliado J osep Renau

${ }^{21}$ Plasmados en la carta enviada a Silva Herzog en julio de 1950. FINISTERRE, Alejandro (1992): "J uan Larrea, León Felipe y el cincuentenario de Cuadernos Americanos", en Cuadernos Americanos, ํo 35. Pág 128

${ }^{22}$ Realidad (1947). Revista de ideas, (3), 3 
No obstante, Realidad va más allá del americanismo defendido por Cuadernos para erigirse claramente en una cabecera universal según el estudio realizado. Dicho universalismo coincide con el defendido por otras publicaciones como Sur de Victoria Ocampo o Revista de Occidente del influyente Ortega (Moreno, 2010, p. 118). Para valorar el grado de americanismo o universalidad se han evaluado tres elementos: el origen de sus colaboradores, las cuestiones abordadas y el alcance de la publicidad e información ofrecida.

Por lo que se refiere a los temas abordados, en Cuadernos es evidente la búsqueda de un mayor y mejor conocimiento de América. En sus cuatro secciones se afrontan constantemente cuestiones relativas al Nuevo Continente. Desde la situación de Iberoamérica tras la II Guerra Mundial, a la investigación sobre la filosofía americana emprendida por Gaos, las cuestiones arqueológicas tanto en México como en Perú, los asuntos económicos o la literatura y pintura locales.

En la década de los años cuarenta, participa en esta revista parte de la elite del continente. Las redes intelectuales creadas permiten la colaboración de una amplísima nómina procedente de casi todos los estados iberoamericanos. Citamos a modo de ejemplo: los desterrados Faustino Miranda, León Felipe, José Gaos, José Medina Echavarría, Pedro Armillas, Manuel Márquez, Eugenio Ímaz, Francisco Giner de los Ríos, Juan David García Bacca, Mariano Ruiz Funes, Joaquín y Ramón Xirau, José Moreno Villa, Juan Ramón Jiménez, Javier Malagón, José Ignacio Mantecón, Agustín Millares Carlo o Luis Santullano. Entre los iberoamericanos firmaron en sus páginas Alfonso Reyes, Daniel Cosío Villegas, José E. Iturriaga, Andrés Henestrosa, Mario de la Cueva, Juan Adolfo Vázquez, Risieri Frondizi, Juan Carlos Ghiano, Carmen R. L. Gándara, Eduardo Mallea, Fryda Schultz de Mantovani, Emilio Sosa López, Tulio Halperin Donghi, Gilberto Freyre, Joaquín García Monge, Víctor Raúl Haya de la Torre, Fernando Ortiz, Juan Marinello, Julio Le Riverend o Loló de la Torriente entre otros muchos.

Realidad aborda cuestiones generales al mundo que presenciaba el inicio de la Guerra Fría, los problemas de la crisis de la cultura de Occidente. No existe esa búsqueda de la identidad América; su mirada va más allá. Sus contenidos giran en torno a la cultura de Occidente, por encima de fronteras estatales o continentales. Al tiempo que analizan cuestiones argentinas 0 de literatura española, abordan problemas de Italia, Austria, Gran Bretaña o Francia, es decir, su línea editorial se dirige a un universalismo evidente. Desde el papel de la mujer inglesa, hasta la educación nazi en Austria, desde las corrientes del pensamiento francés al Martín Fierro, desde el panorama de la novela venezolana a Quevedo.

Este carácter universalista se plasma también en la nómina de colaboradores. Mientras que en Cuadernos Americanos, durante los años estudiados la presencia de escritores europeos es mínima (exceptuando los republicanos desterrados), en Realidad es uno de los pilares fundamentales. Junto a los españoles Corpus Barga, Guillermo de Torre, Francisco Ayala, Lorenzo Luzuriaga, Antonio Espina, José Ferrater Mora, Jesús Prados Arrarte, Adolfo Salazar, Pedro Salinas, José Gaos, Manuel Villegas López, Claudio Sánchez Albornoz, Américo Castro, Segundo Serrano 
Poncela, Joaquín Casalduero, Pedro Bosch Gimpera, Guillermo Díaz Doin, Juan Ramón Jiménez o Rosa Chacel, la nómina de europeos era muy extensa: los británicos George Pendle, Bertrand Russell, Arnold Toynbee y T. S. Eliot, el checoslovaco Hans Kohn, los italianos Max Ascoli, Renato Treves, Norberto Bobbio, Rodolfo Mandolfo, A. C. Jemolo, Guido de Ruggiero, Carlo Carra y Francesco Flora, los alemanes Martin Heidegger y Eduard Spranger así como los franceses Gisele Fraund, Marcel Bataillon, Charles Lalo, J ean Paul Sartre o Emmanuel Berl.

A todos ellos hay que unirle un nutrido grupo de intelectuales iberoamericanos (muchos también presentes en las páginas de Cuadernos) como los argentinos Eduardo Mallea, Ezequiel Martínez Estrada, Miguel Ángel Virasoro, Jorge Luis Borges, Jorge Romero Brest, Ernesto Sábato, Riesieri Frondizi, Julio Cortázar, Luis Emilio Soto o Tulio Halperin Donghi, los peruanos, Wagner de Reyna y Francisco Miró Quesada, los cubanos Virgilio Piñera, Humberto Rodríguez Tomeu o José María Chacón y Calvo así como los brasileños Cecilia Meireles y Otto Carpeaux.

A través de la publicidad se puede conocer el radio de acción, de influencia de las publicaciones, así como las redes intelectuales en las que éstas se insertan. Los anuncios son testimonio del lugar que pretende ocupar la revista en el panorama intelectual local o internacional. La publicidad procedía en gran parte de empresas relacionadas con el mundo editorial establecidas en Argentina para el caso de Realidad (las editoriales Sudamericana, Losada, Argos, América Lee, Poseidón, Rueda, Imprenta López, Depalma, Atlántida, Lautaro, etc.) o de empresas gubernamentales mexicanas o editoriales para Cuadernos Americanos (FCE, Nuevo Mundo, la Nacional Financiera, la Compañía Fundidora de Fierro y Acero de Monterrey, Vidrio Plano SA, Distribuidora Mexicana SA, Aseguradora Mexicana, Altos Hornos de México, Ferrocarriles Nacionales de México o la Lotería Nacional).

La mencionada perspectiva americanista y universalista se aprecia en algunos anuncios procedentes de lugares diferentes al país de impresión. En Cuadernos Americanos se publicita Sur, Realidad y la editorial Losada de Argentina así como Repertorio Americano de Costa Rica. Asimismo, en Realidad se anuncia la Nueva revista de Filología Hispánica editada por el Colegio de México y dirigida por Amado Alonso. Por consiguiente, estos datos nos confirman la amplia difusión que poseían ambas revistas por todo el continente.

Una de los objetivos de estas publicaciones era brindar al lector la actualidad cultural; acercarle obras recién editadas analizadas por expertos para conocer los últimos análisis, estudios, interpretaciones 0 avances científicos, así como las importantes traducciones publicadas en esos años de autores europeos.

En Cuadernos Americanos las recensiones suelen ocupar las últimas páginas de cada una de las cuatro secciones. Su inclusión también fue idea Juan Larrea, para quien estas notas bibliográficas eran un "medio para tocar indirectamente y con 
mirascreadoras los problemas complementarios más interesantes dentro de las posibilidades, desentendiéndose de la crítica corriente de libros" ${ }^{\prime 23}$.

Asimismo, bajo el título de "Notas de libro", Realidad dedica las páginas finales a breves recensiones de obras editadas principalmente en Argentina. A diferencia de Cuadernos Americanos también posee una "Revista de revistas", con especial atención a cabeceras como Les Temps Modernes, la inglesa The Cornhill, Clinamen de Montevideo, Cultura de Río de Janeiro, Cuadernos Americanos o Arbor de Madrid así como una página de libros recibidos.

\subsection{Presencia española}

Esta vocación americanista y universalista no supuso excluir lo español de la revista ya que en Cuadernos Americanos, en opinión de Larrea, forma parte consustancial de América:

La participación española en ese proceso es elemento esencial porque corresponde a su contenido histórico, a la tendencia innata de su destino y al sentido de los acontecimientos actuales servir de puente entre mundo y mundo. De aquí, que su participación en la empresa sea, no instrumental, sino sustantiva. $^{24}$

El decisivo papel de América se basa en lo que deposita de Europa, y concretamente de la España republicana, según Larrea. Define esta realidad como un movimiento acumulativo a través de las civilizaciones, por lo que tras las épocas de Asia y Europa, ahora le toca el turno a América.

En Realidad no existe un reconocimiento a España como tal, sino a Europa. En su presentación explican: "A Europa corresponde el honor de haber concretado nuestra cultura, no sin incluir legados e injertos de otras más viejas"25. Ese universalismo proclamado por la revista de Ayala y Luzuriaga chocaba con una defensa de España como la realizada por Larrea. El papel crucial que había desempeñado la República española en la evolución concebida por Larrea no aparece en Realidad, que influido por el pensamiento de Ayala, huía de cualquier tipo de nacionalismo o localismo.Sin embargo, la nómina de colaboradores españoles es superior a la de otros intelectuales europeos, con una fuerte presencia italiana.

Tanto Realidad como Cuadernos son los primeros ejemplos de cabeceras puente en las que, a pesar de estar impulsadas por exiliados, se da cabida a intelectuales

\footnotetext{
${ }^{23}$ En carta enviada a Silva Herzog en julio de 1950. Finisterre, A. (1992). Juan Larrea, León Felipe y el cincuentenario de Cuadernos Americanos. Cuadernos Americanos ( 35), p. 128

24 Plasmados en la carta enviada a Silva Herzog en julio de 1950. Finisterre, A. (1992). Juan Larrea, León Felipe y el cincuentenario de Cuadernos Americanos. Cuadernos Americanos ( 35), p. 128

${ }^{25}$ Realidad. Revista de ideas, no 3, 1947. Pág. 2
} 
establecidos en el interior de España ${ }^{26}$. En un momento en el que la España Peregrina y la España del interior estaban totalmente separadas e incluso enfrentadas, Larrea, Ayala y Luzuriaga permiten una ligera apertura de sus revistas a otros colegas españoles, siempre y cuando se tratasen de intelectuales respetuosos con los principios democráticos. Esta decisión es consecuencia de ese americanismo y universalismo propugnado en ambas que imprimía una concepción abierta de la nómina de colaboradores.

En Cuadernos Americanos durante los años 1942-1949, el único colaborador de la España del interior fue el alicantino Pascual Pla y Beltrán. Sin embargo, ya a partir de los años cincuenta participaron José Luis Cano, Gabriel Celaya, Juan y Agustín Goytisolo o J aime Gil de Biedma.

En Realidad, ya en el tercer número hay una "Carta de España" firmada por "Un corresponsal", quizás José Luis Cano, piedra angular del puente entre el interior y el exilio. Esta "Carta de España" en sucesivas ocasiones daría cuenta del ambiente literario español como la novela Nada, o la obra de Gironella y Camilo José Cela así como del panorama de revistas del interior. Previamente, en el número inicial Ayala había comentado la mencionada novela de Carmen Laforet para reconocer la existencia de pequeños brotes verdes que surgían en el páramo del interior. Finalmente, en el no 7 firma "Carta de España" Ricardo Gullón se atreve a firmar desde el interior una crónica del panorama literario español y denunciar "la crisis de la crítica en España" por el compadreo que existe y desvirtúa las opiniones.

\section{CONCLUSIÓN}

En ambos casos estamos ante cabeceras que no se limitan a reflejar los problemas, realidades 0 debates de Argentina o México, sino que abordan las cuestiones continentales e incluso comunes a las preocupaciones europeas, es decir, universales, según su idea. Huyen de cualquier nacionalismo o localismo (sea éste español, argentino o mexicano) para erigirse como portavoces de la actualidad cultural iberoamericana, Cuadernos Americanos, y mundial, Realidad ${ }^{27}$.

En este sentido, coinciden con esa voluntad continental de Cuadernos otras publicaciones de la época como Sur, Revista de Indias o Repertorio Americano. Aprovechando la comunicación en castellano se convirtieron en foros de debates entre países tan lejanos como México o Argentina, algo impensable en el continente europeo.

\footnotetext{
${ }^{26}$ También en los años cincuenta Las Españas y el Boletín de información de la Unión de Intelectuales Españoles, ambas editadas en México, se abrirían a otros intelectuales del interior

${ }^{27}$ Recuerda Ayala: "Mientras que me esforzaba por mantener el tono predominantemente intelectual de la revista, debía defenderla contra las tendencias nacionalistas de la señora Gándara, quien, cada vez que nos reuníamos en comité asesor, se lamentaba de su falta de 'raíces' e insistía en la necesidad de convertirla en expresión genuina de 'lo argentino', de 'lo nuestro', sin que - pese a mi curiosidad inquisitiva- hubiera nunca manera de averiguar qué era 'lo argentino' y 'lo nuestro'". AYALA, Francisco (2001): Recuerdos y olvidos. Madrid. Alianza Editorial. Pág. 344
} 
Es evidente que estas revistas fueron clave en el desarrollo cultural del Continente ya que sirvieron tanto como plataforma, soporte de la producción científica y cultural iberoamericana, como de penetración de ensayos de las principales firmas mundiales como Heiddeger o Sartre. A pesar de contar con una identidad propia, en ningún caso ejercieron como sustentos monolíticos, sino que ofrecieron una pluralidad de ideas y perspectivas como atestiguan las polémicas plasmadas en ambas (Larrea- Iturriaga, Ayala-Claudio Sánchez Albornoz). La lectura de sus páginas permite determinar cuáles eran las preocupaciones del momento: el mundo tras la II Guerra Mundial, el papel de Iberoamérica en dicho contexto, la posición del intelectual, la tecnología y los acuerdos económicos. En Cuadernos todo ello se afronta desde una perspectiva más americanista frente al modo universalista de abordar dichas cuestiones en Realidad.

Actuaron como nodos de las redes intelectuales establecidas entre tres puntos: Iberoamérica, Europa y la España del interior, lejos de erigirse en revistas nacionalistas o localistas por la ideología de sus impulsores.

Tanto Cuadernos como Realidad confirman la apertura de una parte del exilio establecido en América hacia el Nuevo Continente. Es muy probable que sin el éxodo de la Guerra Civil, ninguna de estas publicaciones hubiera visto la luz ni tampoco se hubiera originado un contacto tan fructífero entre los colaboradores de estas cabeceras.

\section{BIBLIOGRAFÍA}

Ayala, F. (2001). Recuerdos y olvidos. Madrid: Alianza Editorial.

de Zuleta, E.(1983). Relaciones literarias entre España y la Argentina. Madrid: Ediciones Cultura Hispánica del Instituto de Cooperación Iberoamericana.

Ferriz Roure, T. (2002) Estudio de España Peregrina. Consultado el 23 de enero de 2007, Disponible en:

www.cervantesvirtual.com/servlet/SirveObras/03695030900370528539079/index.htm

Finisterre, A. (1992). Juan Larrea, León Felipe y el cincuentenario de Cuadernos Americanos. Cuadernos Americanos, (35), 119-133.

García Montero, L. (2007).Realidad. Revista de ideas. Sevilla: Renacimiento. Edición facsimilar.

García Montero, L. (2009): El escritor en su siglo. Granada: Diputación.

González Neira, A. (2010). Prensa del exilio republicano (1936-1977). Santiago: Andavira.

Guber, R. (1999). Occidente desde la Argentina. "Realidad" y ficción de una oposición constructiva. En N. Girbal-Blacha \& D. Quattrocchi-Woisson (Eds.): 
Cuando opinar es actuar. Revistas argentinas del siglo XX.(pp. 363-397) Buenos Aires. Academia Nacional de la Historia.

Ignacio S. (1966). Francisco Ayala: Respuestas a un cuestionario. Consultado el 15 de febrero de 2010, Disponible en:

http://www.juntadeandalucia.es/cultura/bivian/media/ayala/respuestas_a_un_cuestio nario.htm

Krauel, J. (2006). El problema de España en el exilio: indagación de una polémica en las páginas de Realidad (1947-1949). En M. Aznar (Ed.), Escritores, editoriales y revistas del exilio republicano de 1939( 931-938), Sevilla: Renacimiento.

Macciuci, R. (2010). Entrelíneas: memorias y exilio argentino de Francisco Ayala" en M. Cabañas, Analogías en el arte, la literatura y el pensamiento del exilio español de 1939(261-270). Madrid: CSIC.

Moreno Herrera, L. (2010). La invención de una cultura literaria: Sur y orígenes. Dos revistas latinoamericanas del siglo XX. México. Memoria de tesis del Posgrado en estudios latinoamericanos.

Weinberg, L. (1995). Cuadernos Americanos: entre la memoria y la imaginación Cuadernos Americanos, (50), 13-22.

Weinberg, L. (2010). Cuadernos Americanos: la política editorial como política cultural. En C. Altamirano, (ed.), Historia de los intelectuales en América Latina. I/ Los avatares de la 'ciudad letrada' en el siglo XX (235-258I). Buenos Aires: Katz Editores.

Weinberg, L. (2010). El encuentro de un escritor y una revista: Alfonso Reyes y Cuadernos Americanos. En R. Crespo. Revistas en América Latina: proyectos literarios, políticos y culturales (293-318). México: CI ALC.

\section{Ana González Neira}

Doctora en Periodismo y licenciada en Periodismo y CC Políticas así como master en Relaciones Internacionales. En la actualidad es ayudante doctora en la Facultad de Comunicación de la Universidade da Coruña. Ha sido profesora en la Universidad de Génova (Italia) y en Madrid. Sus líneas de investigación se centran en estrategias de manipulación y desinformación de los media así como en la historia de los medios de comunicación, especialmente en la prensa del exilio español, sobre lo que acaba de publicar un libro. Ha colaborado con diversos artículos en revistas de América y Europa y ha participado en proyectos de investigación internacionales. 